
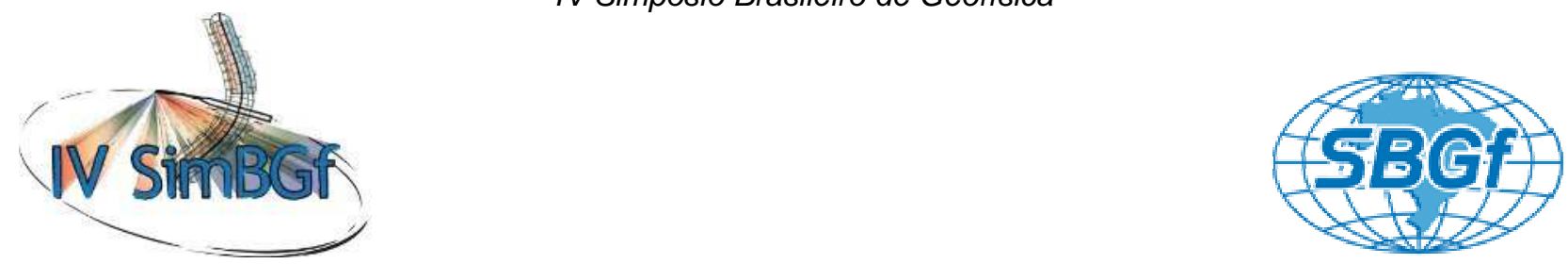

\title{
Utilização de Perfis de Ressonância Nuclear Magnética para Identificação de Hidrocarbonetos na Bacia Potiguar.
}

Álvaro Francisco Campassi Reis, PETROBRAS.

Copyright 2010, SBGf - Sociedade Brasileira de Geofísica

Este texto foi preparado para a apresentação no IV Simpósio Brasileiro de Geofísica, Brasília, 14 a 17 de novembro de 2010. Seu conteúdo foi revisado pelo Comitế Técnico do IV SimBGf, mas não necessariamente representa a opinião da SBGf ou de seus associados. É proibida a reprodução total ou parcial deste material para propósitos comerciais sem prévia autorização da SBG.

\section{Resumo}

A avaliação petrofísica convencional por perfis baseia-se no contraste de resistividade entre zonas portadoras de hidrocarbonetos de alta resistividade e zonas portadoras de água da formação salobras de baixa resistividade. A ocorrência de reservatórios portadores de água de baixa salinidade demanda a utilização de ferramentas não convencionais capazes de identificar petróleo independente do contraste de resistividade. Os perfis de Ressonância Nuclear Magnética (RNM) são empregados nesse contexto em poços exploratórios na Fm Açu (Albiano) e Alagamar (Aptiano) da Bacia Potiguar emersa. Os perfis de RNM tem sido utilizados com dupla função: identificação de hidrocarbonetos e caracterização da qualidade do reservatório.

\section{Introdução}

A Bacia Potiguar situa-se na porção mais oriental do nordeste do Brasil, na margem equatorial brasileira (figura 1). Abrange porções emersas $(22.500 \mathrm{Km} 2)$ e submersas (26.500 Km2) dos estados do Rio Grande do Norte e Ceará. A bacia é limitada a sul, leste e oeste por rochas do embasamento cristalino, ao norte com 0 Oceano Atlântico e a noroeste com o alto de Fortaleza

A gênese e evolução da Bacia Potiguar relacionam-se ao desenvolvimento da margem equatorial atlântica, iniciada no final do Jurássico. A rotação diferencial dextral entre a América do Sul e África gerou um regime de esforços com distensão norte-sul e compressão leste-oeste, propiciando o desenvolvimento de diversas bacias rifte em regimes transtensionais (Françolim \& Szatmari 1987). A evolução tectono-sedimentar da bacia pode ser dividida, de forma geral, em três fases principais: rifte, transicional, e deriva continental. $\mathrm{Na}$ fase transicional (neoaptiano) foram depositados os carbonatos e arenitos deltáicos de ambiente lagunar restrito, com influência marinha, da Formação Alagamar. $\mathrm{Na}$ fase de deriva continental (albiano) foram depositados os arenitos e folhelhos de ambiente fluvial da Formação Açu.

$\mathrm{Na}$ Bacia Potiguar emersa boa parte das acumulações de hidrocarbonetos ocorre associada a água de formação de baixa salinidade (abaixo de 1000 ppm $\mathrm{NaCl}$ ). Incluindo os reservatórios silissiclásticos da $\mathrm{Fm} A c ̧ u$, que apresentam porosidades médias acima de $21 \%$ e regulares a altas permeabilidades.

A Fm Alagamar caracteriza-se pela presença de reservatórios argilosos depositados em ambiente deltalacustrino. Apresentam porosidades médias abaixo de $20 \%$ e baixas permeabilidades. A associação com água da formação doce a salobre e a presença de argila laminar constituem um desafio para a avaliação de formação. A permeabilidade do reservatório, devido a presença de argilominerais, não mantém relação linear com a porosidade indicada pelos perfis convencionais, critério qualitativo ainda largamente utilizado na definição de zonas de interesse por perfis. O conhecimento da porosidade, portanto, não é um parâmetro suficiente para definir zonas de interesse. Os perfis elétricos, por sua vez, devido a argilosidade do reservatório e as baixas salinidades da água da formação, não distinguem claramente zonas portadoras de hidrocarbonetos.

Neste trabalho são discutidos resultados obtidos através da corrida do perfil de Ressonância Magnética em quatro poços representando reservatórios da FM Açu e Alagamar.

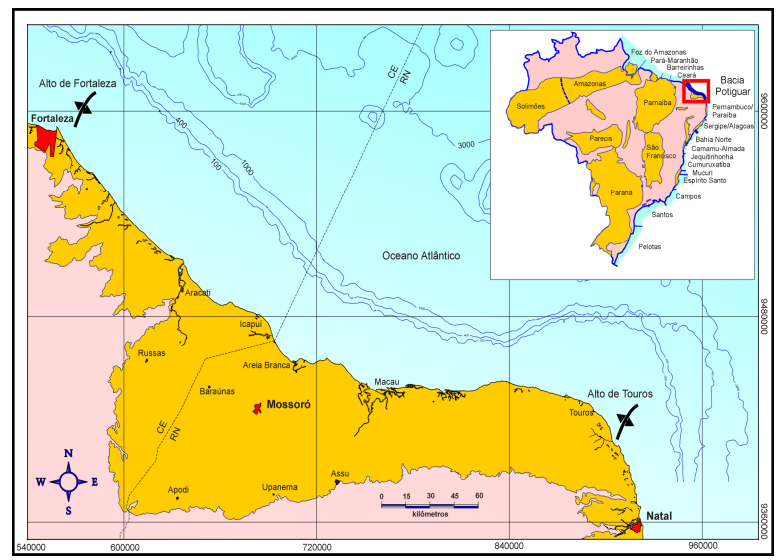

Figura 1 - Mapa de Localização da Bacia Potiguar.

\section{Metodologia}

O princípio físico das medidas de ressonância magnética consiste na polarização dos átomos de hidrogênio contido somente nos poros das rochas (água, óleo ou gás) por um magneto permanente integrante da 
ferramenta e sucessivas medições do tempo de decaimento ou relaxamento (Coates et al., 1999).

O hidrogênio, por constituir-se em um próton e um elétron, comporta-se como um pequeno imã e alinha-se paralelamente ao campo magnético da ferramenta. $O$ tempo necessário para o total alinhamento dos "spins" de hidrogênio é uma propriedade da rocha conhecida como tempo de polarização (T1). O tempo de polarização varia com a distribuição do tamanho dos poros e com a viscosidade do fluido não molhante. Após a polarização dos fluidos contidos na rocha, a ferramenta passa a emitir pulsos de radiofreqüência que rebatem os "spins" de hidrogênio para um plano transversal. Nesse plano transversal, através de uma sucessão de pulsos de radiofreqüência a $90^{\circ}$ e $180^{\circ}$, é realizada a medição do tempo de relaxamento (T2). Para cada pulso emitido pela ferramenta obtém-se um sinal de ressonância daqueles "spins" de hidrogênio que permanecerem polarizados. Ao longo do tempo 0 sinal tende a declinar exponencialmente. O tempo de relaxamento T2 é função da distribuição do tamanho de poros, viscosidade da fase não molhante e difusividade dos fluidos (figura 2).

Existem vários métodos descritos na literatura para identificar e mesmo quantificar hidrocarbonetos a partir de técnicas envolvendo perfis de ressonância magnética. Estas técnicas exploram 0 contraste entre as propriedades T1 e T2 dos diversos fluidos presentes no reservatório (Moraes et al., 2000, Decoster et al., 2008).

A técnica de Difusão (Akkurt, R. et al., 1996) explora o contraste de difusão entre a água e o óleo imposto pela adoção de um tempo entre ecos (TE) elevado separando as duas fases em perfil (figura 3). A difusão, corresponde ao relaxamento, ou perda de polarização, causada pela movimentação dos "spins" de hidrogênio no interior do fluido. É função da viscosidade, temperatura e tipo de fluido .A técnica de difusão vem sendo utilizada com sucesso na Bacia Potiguar para identificação de hidrocarbonetos independentemente da salinidade da água da formação.

A corrida do perfil inicia-se com o planejamento da operação feita no escritório. Nessa etapa são levantadas as informações referentes ao tipos de fluidos, viscosidade, temperatura, tipo de reservatório, fluido de perfuração porosidade e saturação esperadas. Com essas informações seleciona-se a ativação: conjunto de parâmetros de aquisição, apropriada para atender os objetivos da corrida do perfil.

No escritório é posteriormente realizado um processamento da curva de distribuição de T2 adquirida no campo. É possível alterar-se o "cut-off" de T2, valor que separa o volume de fluido livre do volume do fluido irredutível. São calculadas a argilosidade, porosidade, volume de água irredutível, fluido móvel e permeabilidade a partir do "cut-off" ajustado. O volume de óleo é calculado a partir do processamento do espectro de difusão, onde é analisado o limite de difusão da água e calculado o volume de óleo na zona invadida (sxo).

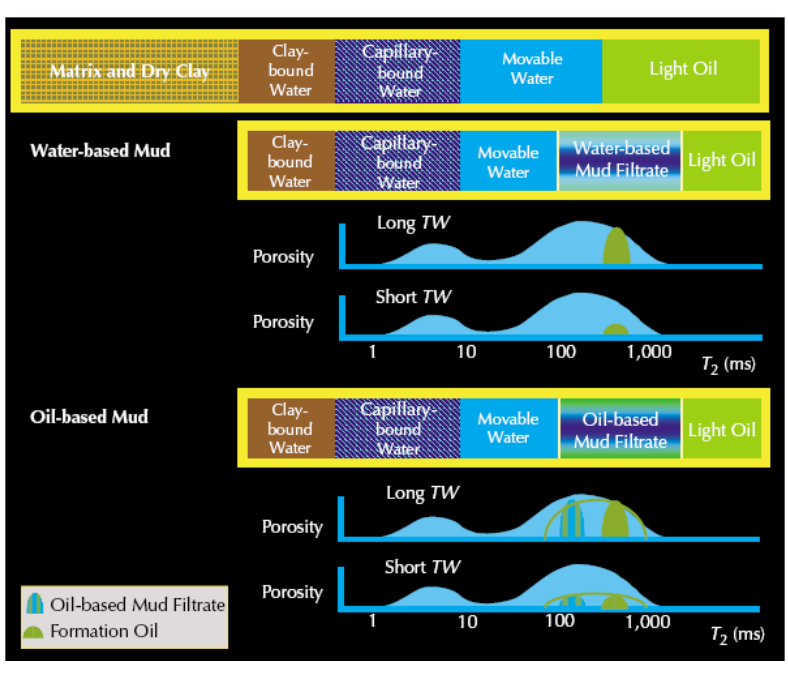

Figura 2 - Distribuição do espectro de T2 de acordo com tamanho de poros e fluidos presentes no reservatório. Coates 1999.

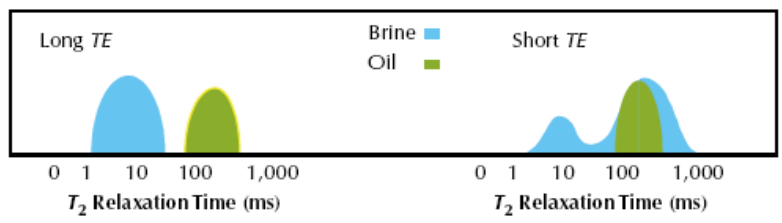

Figura 3 - Distribuição do espectro de difusão (Long TE) vs T2 (Short TE.) Coates 1999.

\section{Resultados}

O poço A constatou a presença de óleo em reservatório arenoso da Fm Açu próximo a um intervalo portador de água. Por perfis o reservatório apresenta porosidade de $30 \%$, a permeabilidade medida em teste de formação foi $36 \mathrm{mD}$. A ferramenta de Ressonância Nuclear Magnética foi corrida com o objetivo de identificação de fluido da formação e caracterização de parâmetros de reservatório.

Na figura 04 observa-se na trilha 03 o espectro de T2, na trilha 04 o espectro de difusão e na trilha 05 os volumes de água adsorvida nas argilas (hachureado em verde) correspondente ao T2 entre $0,5 \mathrm{~ms}$ e $3 \mathrm{~ms}$; o volume de água irredutível (hachureado em cinza) correspondente ao T2 entre $3 \mathrm{~ms}$ e $33 \mathrm{~ms}$; volume de fluido livre (hachureado em azul) correspondente ao T2 maior do que $33 \mathrm{~ms}$ e o volume de óleo na zona invadida (hachureado em preto) correspondente ao T2 maior do que $100 \mathrm{~ms}$ no espectro de difusão. Ocorrem dois reservatórios no poço $A$ no topo e na base, separados por um folhelho. Apenas o reservatório superior apresenta saturação de óleo, conforme mostra o espectro de difusão (trilha 04). O intervalo superior foi avaliado por teste de formação a poço revestido produzindo óleo de densidade equivalente a $26^{\circ} \mathrm{API} / 60 \mathrm{~F}$ livre de BSW. A curva de permeabilidade derivada da distribuição de T2 
(modelo Timur-Coates) está apresentada na trilha 2. Para o intervalo superior os valores oscilam entre 10 a 100 $\mathrm{mD}$, consistente com o valor medido em teste.

No poço $B$ foi testado a poço revestido um reservatório arenoso pertencente a Fm Açu cuja avaliação dos perfis convencionais indicava uma possível zona de interesse para óleo com porosidade de $20 \%$. A ferramenta de Ressonância Nuclear Magnética foi corrida com 0 objetivo de identificação de fluido da formação e caracterização de parâmetros de reservatório.

$\mathrm{Na}$ figura 05 observa-se igualmente na trilha 030 espectro de T2, na trilha 04 o espectro de difusão e na trilha 05 os volumes de água adsorvida nas argilas (hachureado em verde) correspondente ao T2 entre $0,5 \mathrm{~ms}$ e $3 \mathrm{~ms}$; o volume de água irredutível (hachureado em cinza) correspondente ao T2 entre $3 \mathrm{~ms}$ e $33 \mathrm{~ms}$; volume de fluido livre (hachureado em azul) correspondente ao T2 maior do que $33 \mathrm{~ms}$ e o volume de óleo na zona invadida (hachureado em preto) correspondente ao T2 maior do que $100 \mathrm{~ms}$ no espectro de difusão. O intervalo canhoneado para execução do teste de formação está indicado à direita da trilha 05 . Observa-se na trilha 05 o pequeno volume de fluido livre e o proporcionalmente maior volume de água adsorvida nas argilas, indicando a má qualidade do reservatório. A permeabilidade derivada da distribuição de T2 (trilha 2) encontra-se abaixo de $1 \mathrm{mD}$. Não foi constatado volume de óleo na zona invadida no espectro de difusão. O resultado do teste de formação executada nessa zona confirma as características do reservatório segundo o perfil de Ressonância Magnética. A interpretação do teste indicou um reservatório de baixíssima permeabilidade sem produção de fluidos da formação.

A mesma zona avaliada no poço $B$ foi atravessada pelo poço C com características permo-porosas mais favoráveis conforme indica o perfil de RNM apresentado na figura 06.

$\mathrm{Na}$ figura 06 pode-se observar o intervalo canhoneado (trilha 05) na mesma zona investigada no poço anterior. A porosidade nesse caso alcança $24 \%$ e há proporcionalmente menos argilosidade em relação ao volume de fluido livre. A curva de permeabilidade indica valores em torno de $10 \mathrm{mD}$ e, de acordo com a distribuição do espectro de difusão, há saturação de óleo na zona invadida. O teste de identificação de fluido confirmou a informação do perfil de RNM com produção de óleo de densidade equivalente a 24 API/60 F.

O poço $D$ constatou a presença de óleo em reservatório arenoso da Fm Alagamar em intervalo considerado portador de água segundo avaliação convencional. Por perfis o reservatório apresenta porosidade de $24 \%$. A permeabilidade medida em teste de formação foi $4 \mathrm{mD}$. A ferramenta de Ressonância Nuclear Magnética foi corrida com o objetivo de identificação de fluido da formação, presença de contato óleo/água e caracterização de parâmetros de reservatório.

Na figura 07 observa-se na trilha 03 o espectro de T2, na trilha 04 o espectro de difusão e na trilha 05 os volumes de água adsorvida nas argilas (hachureado em verde) correspondente ao T2 entre $0,5 \mathrm{~ms}$ e $3 \mathrm{~ms}$; o volume de água irredutível (hachureado em cinza) correspondente ao T2 entre $3 \mathrm{~ms}$ e $33 \mathrm{~ms}$; volume de fluido livre (hachureado em azul) correspondente ao T2 maior do que $33 \mathrm{~ms}$ e o volume de óleo na zona invadida (hachureado em preto) correspondente ao T2 maior do que $100 \mathrm{~ms}$ no espectro de difusão. A base do intervalo, cuja avaliação convencional indicava saturação de água, foi avaliado por teste de formação a poço revestido produzindo óleo de densidade equivalente a $34^{\circ} \mathrm{API} / 60 \mathrm{~F}$ livre de BSW, confirmando a indicação do perfil de RNM. Após esse resultado o canhoneio foi ampliado para o topo do intervalo e estimulado por fraturamento hidráulico.

\section{Discussão e Conclusões}

A presença de reservatórios portadores de hidrocarbonetos associados à ocorrência de argila laminar e água de formação de baixa salinidade constituem um desafio para a interpretação de perfis e avaliação de formação, devido a ausência ou limitado contraste de resistividade entre zonas portadoras de hidrocarbonetos e água da formação. Nesse cenário recomenda-se a utilização da ferramenta de Ressonância Nuclear Magnética para identificação de hidrocarbonetos alternativamente às ferramentas de resistividade.

Adicionalmente os perfis de Ressonância Nuclear Magnética agregam informações sobre a qualidade do reservatório não detectadas pelos perfis convencionais. Nos reservatórios argilosos associados a água de baixa salinidade da Fm Alagamar a porosidade isoladamente não é um bom indicador da qualidade do reservatório. $\mathrm{Na}$ Fm Açu, em algumas situações, os perfis elétricos sugerem qualitativamente a ocorrência de óleo em reservatórios de baixa permeabilidade portadores de água.

As propriedades permoporosas e identificação de hidrocarbonetos fornecida pelos perfis de Ressonância Nuclear Magnética foram confirmadas pelos testes de formação realizados nos quatro poços apresentados e em situações semelhantes na Bacia Potiguar.

A principal limitação da utilização de perfis de Ressonância Nuclear Magnética é a pequena profundidade de investigação das ferramentas disponíveis no mercado (inferior a 4 polegadas), restringindo sua investigação à zona invadida pelo filtrado do fluido de perfuração.

A técnica de difusão discutida nesse trabalho é indicada para reservatórios portadores de óleo e sensível à sua viscosidade. O range de viscosidade aplicável varia entre 1 a $50 \mathrm{cp}$

\section{Referências}

Akkurt, R., et ali. 1996. Determination of residual oil saturation using enhanced diffusion - SPE 49014 SPE Annual Techinical Conference 268-77. 
Coates, G.R., Xiao, L., Prammer, M.G. 1999. NMR logging principles and applications. Halliburton publication H02308.

Decoster, E., Carmona, R. 2008. Application of Recent NMR Developments to the Characterization of Ori-noco Belt Heavy Oil Reservoirs, SPWLA49th Annual Logging Symposium,Edimburgo.
Françolim, J. B. L. \& Szatmari, P. 1987. Mecanismo de rifteamento da porção oriental da margem norte brasileira. Revista Brasileira de Geociências, v.17, n.2, p.196-207.

Moraes, J. J., et ali. 2000. NMR Logging improves wellsite efficiency, completion decisions, and formation evaluation in a freshwater, shaly reservoir. - SPE 63213 SPE Annual Techinical Conference 1-9.

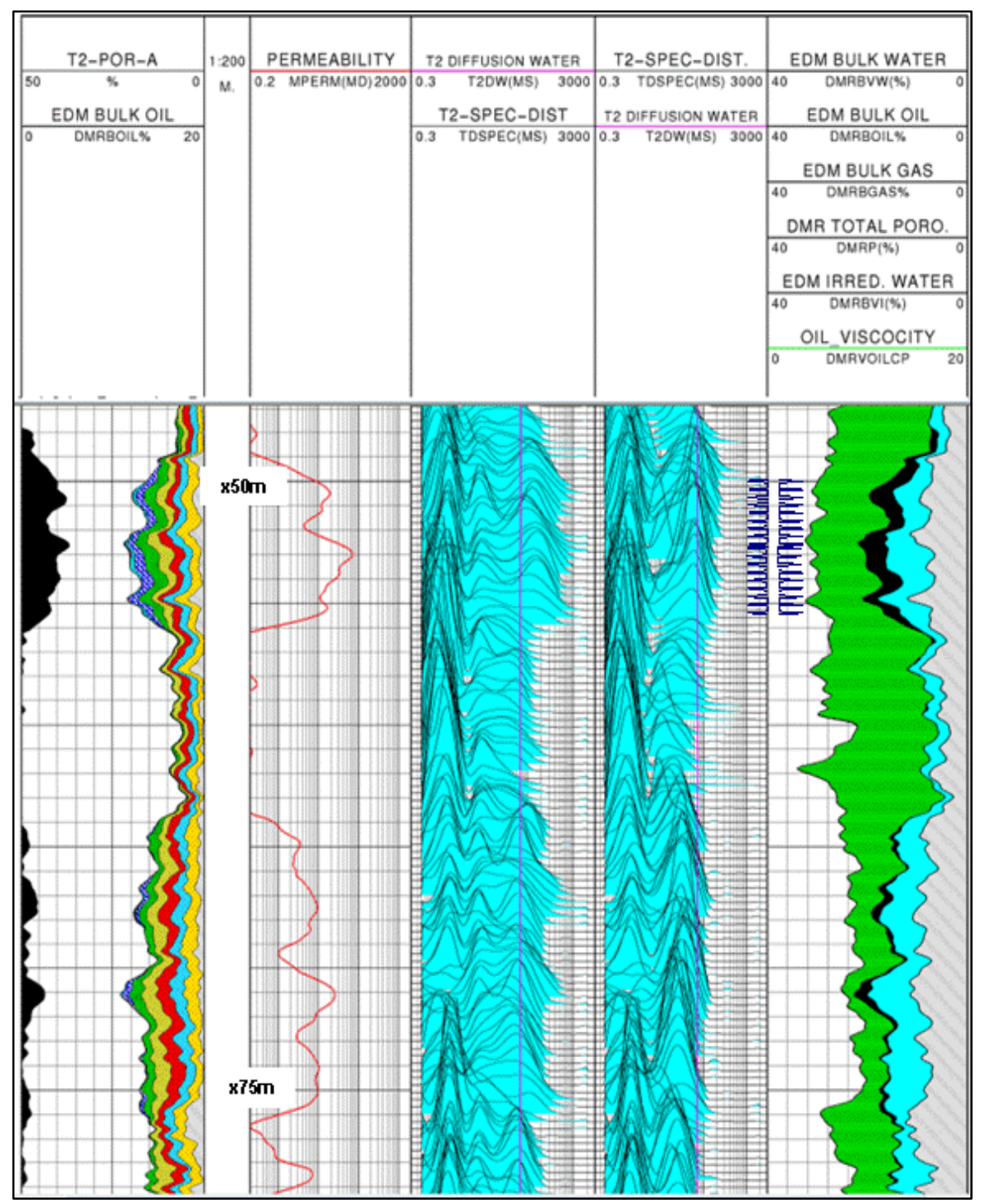

Figura 4 - Perfil de Ressonância Nuclear Magnética. Poço A. Espectros de difusão e T2. 


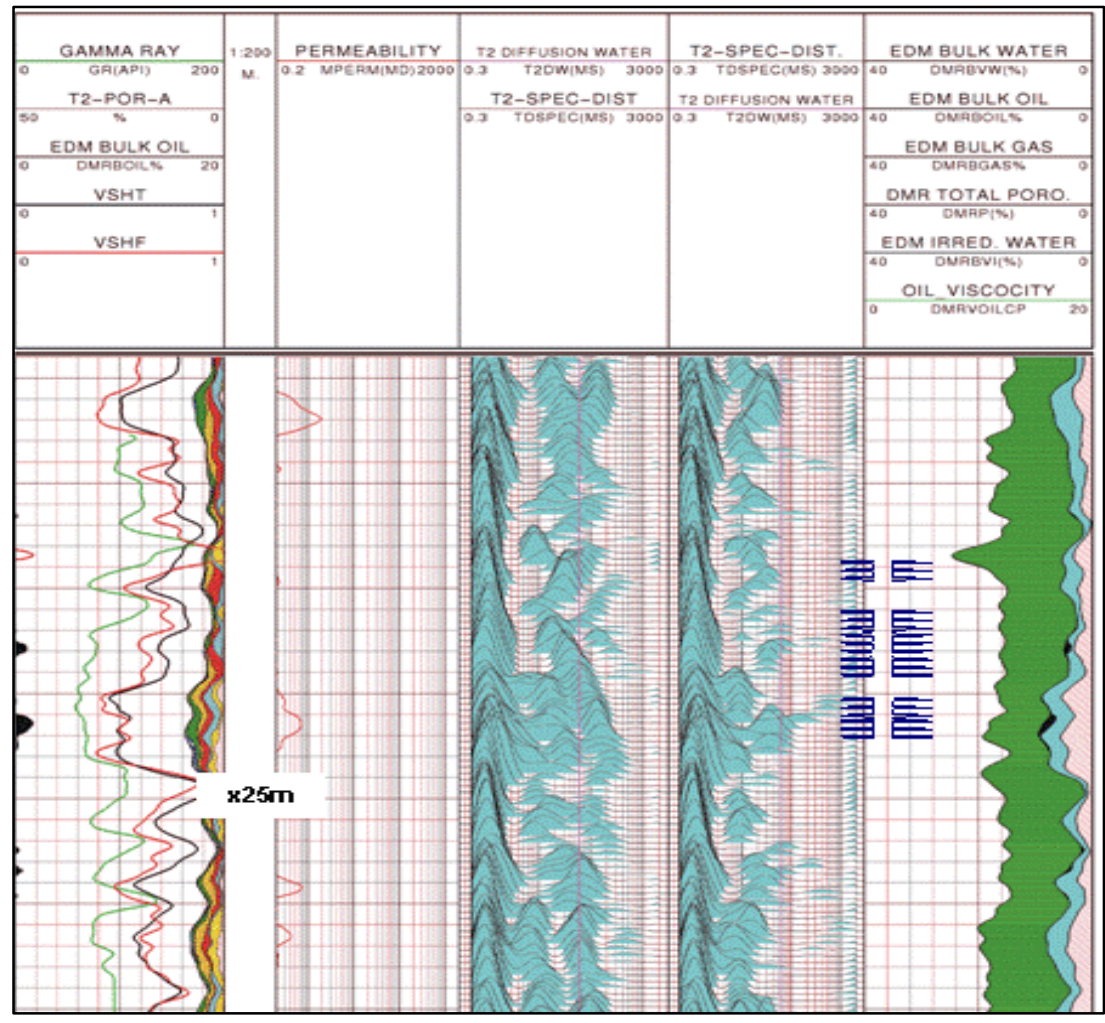

Figura 5 - Perfil de Ressonância Nuclear Magnética. Poço B. Espectros de difusão e T2.

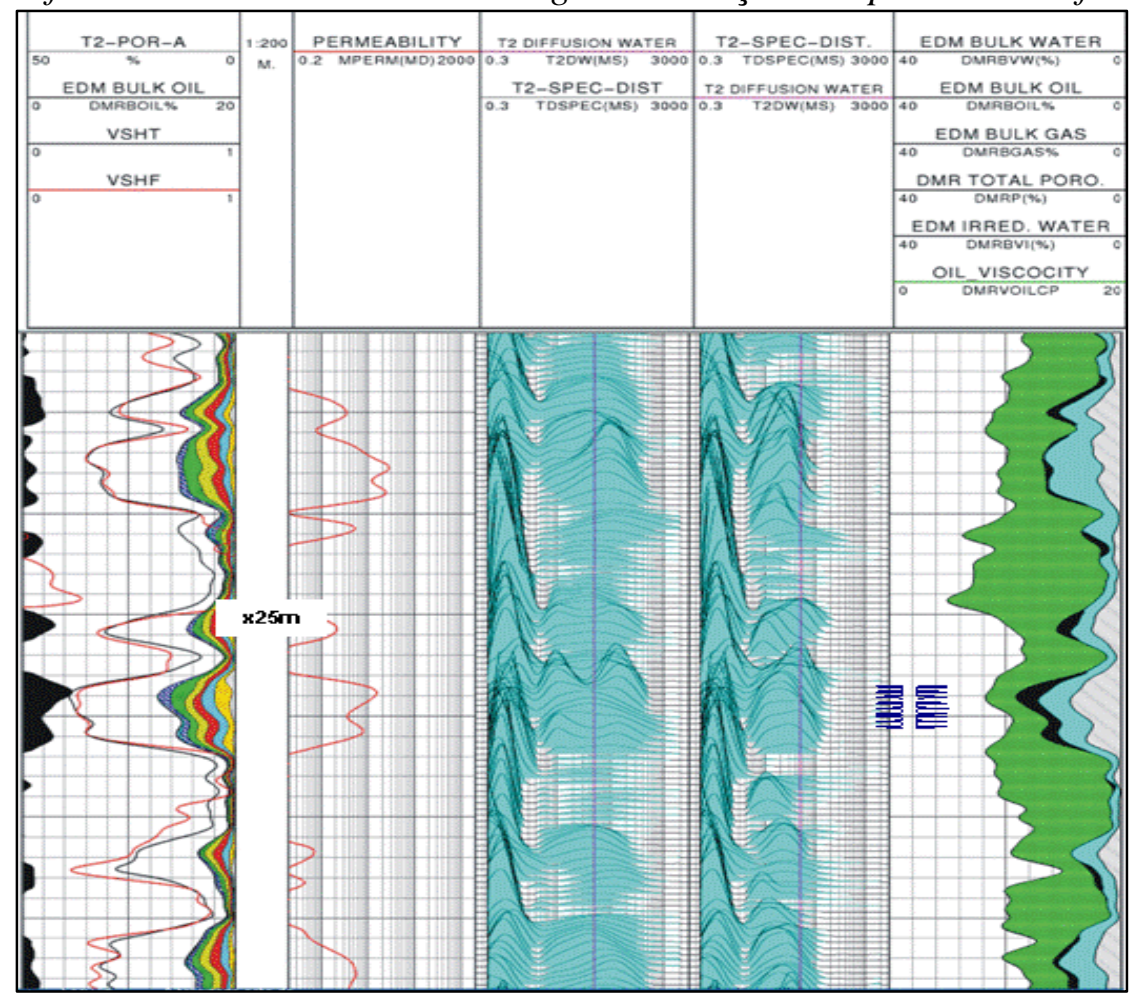

Figura 6 - Perfil de Ressonância Nuclear Magnética. Poço C. Espectros de difusão e T2. 


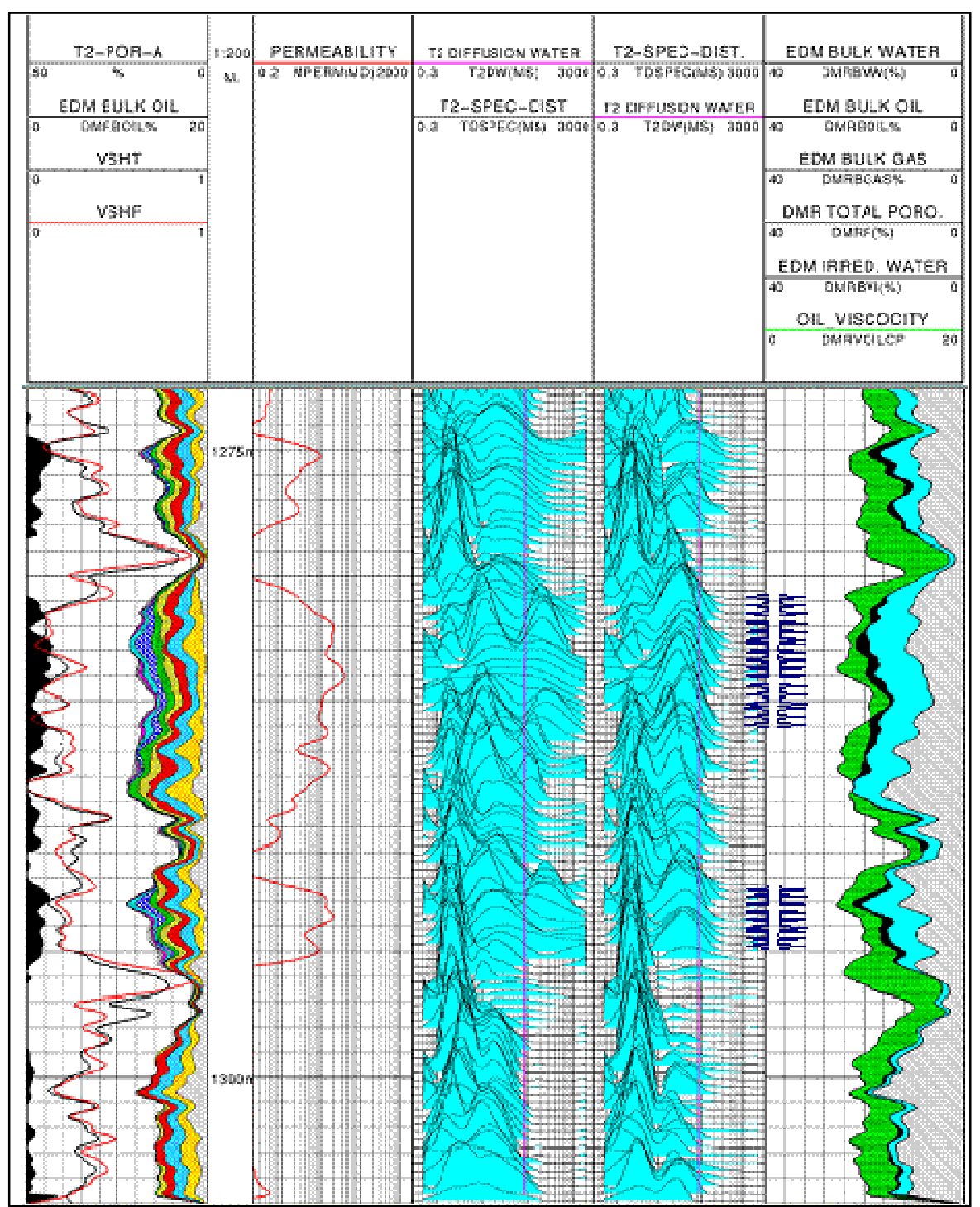

Figura 7 - Perfil de Ressonância Nuclear Magnética. Poço D. Espectros de difusão e T2. 